\title{
Morphology of Mycoplasma mycoides Thread-phase Growth
}

\author{
By R. N. GOURLAY AND K. J. THROWER \\ A.R.C. Institute for Research on Animal Diseases, Compton, Newbury, Berkshire
}

(Accepted for publication 2I June 1968)

SUMMARY

Examination of threads of Mycoplasma mycoides var. mycoides by optical and electron microscopy revealed organisms within a homogeneous mucinous matrix. This matrix stained with the periodic acid-Schiff (PAS) reagent method was almostelectron-transparent and was probably lipo-polysaccharide (galactan) material. Treatment of threads with specific antibody produced a clearly visible microscopic precipitate strongly outlining the threads. By electron microscopy this precipitate was electron-dense, homogeneous, and finely granular; it could frequently be seen surrounding individual mycoplasma cells as a well-defined capsule.

\section{INTRODUCTION}

Tang, Wei, McWhirter \& Edgar (1935) described the formation of 'islands' and 'threads' visible to the naked eye during the growth of Mycoplasma mycoides var. mycoides in liquid medium. Later, Turner (1959) called them 'masses of intricately branched mycelial filaments' and described them as 'whitish, translucent, elongated objects which may hang from the surface of the medium or from the walls of the tube, or may originate from a mucinous deposit at the bottom. On removal from the incubator, convection currents cause them to circulate slowly through the crystal-clear medium as easily deformable, elongated objects recalling wisps of smoke. As incubation proceeds, these "wispy growths" become dispersed and growth becomes diffuse throughout the medium.' The morphology of the thread has been largely ignored, although the mycelial filaments which form the threads have been studied intensively. This present paper describes studies on threads of $M$. mycoides before and after the addition of specific antibody.

\section{METHODS}

Mycoplasma mycoides. The T2 vaccine strain (Piercy \& Knight, 1956) was used. Threads were grown in modified Newing's tryptose broth (Gourlay, 1964) which contained $0.5 \%$ glucose.

Microscopical examination. Threads were removed from the broth with a Pasteur pipette and were either placed intact or gently spread on a glass slide. The preparations were air-dried and fixed in Schaudin's fluid and then stained overnight with $10 \%$ Giemsa or by the periodic acid-Schiff (PAS) reagent method, followed by Giemsa. Slides were examined by light microscopy. Wet preparations under a coverslip were examined by dark-ground and phase-contrast microscopy.

Electron-microscopical examination. Threads were placed in $3 \%(\mathrm{v} / \mathrm{v})$ glutaraldehyde for about $18 \mathrm{hr}$, washed in $0.1 \mathrm{M}$-phosphate buffer $(\mathrm{pH} \mathrm{7.3)}$ for about $7 \mathrm{hr}$, and finally put into $\mathrm{I} \%(\mathrm{w} / \mathrm{v})$ osmium tetroxide in $0 . \mathrm{I}$ M-phosphate buffer $(\mathrm{pH} 7 \cdot 3)$ for about 
I $8 \mathrm{hr}$. After fixation the threads were washed briefly in distilled water and embedded in $2 \%$ agar at $45^{\circ}$. Pellets of agar containing the threads were then dehydrated and embedded in Araldite. Sections were cut with a Reichert OMU 2 ultra-microtome, stained with uranyl acetate and examined with a Philips EM 75 electron microscope.

The effect of specific antibody and complement. Immediately after removal from the liquid medium threads were placed into undiluted anti- $M$. mycoides hyperimmune sheep serum (Gourlay, 1964) previously heated at $56^{\circ}$ for $30 \mathrm{~min}$. or into $2 \cdot 2 \%$ globulin in phosphate-buffered saline ( $\mathrm{pH} 7 \cdot 2)$ precipitated by ammonium sulphate from the sheep serum. Complement, as $20 \%$ fresh guinea-pig serum, was occasionally added to the serum before the addition of the threads. Threads were left in the serum at room temperature for $90 \mathrm{~min}$. and then removed and fixed as described above. Occasionally, incubation of the thread and antiserum was done on a glass slide under a coverslip and the reaction observed by dark-ground and phase-contrast microscopy. Controls were set up with normal sheep serum and inactivated guinea-pig serum.

\section{RESULTS}

\section{Growth characteristics of threads in broth}

When about $10^{9}$ organisms were inoculated into broth in serial tenfold dilutions, growth usually occurred in the low dilutions within I to 2 days, as a diffuse turbidity, and in the higher dilutions by day 4 or 5 . The characteristic growth in these higher dilutions was the appearance of one or more white, translucent, pear-shaped 'islands' from which threads developed. The threads lengthened and thickened, sometimes attaining a length of about $3 \mathrm{~cm}$. and a thickness of about $\mathrm{I} \mathrm{mm}$. The islands and threads could be easily seen suspended in the clear medium (PI. I, fig. I). After further incubation the threads slowly dispersed and the medium became opaque with a a mucinous deposit at the bottom of the tube.

\section{Examination of threads}

Optical microscopy. The slightly mucinous consistency of the thread could be seen when it was lightly spread on a glass slide. Under the low power of the microscope smears stained with PAS-Giemsa showed a bright red-streaked mucinous mass in which the more deeply stained purple mycelial filaments and groups of organisms could be discerned (P1. I, fig. 2). Under high power of the microscope, Giemsa-stained smears showed a mass of deeply staining mycoplasma cells apparently held in a faintly staining homogeneous matrix (Pl. I, fig. 3).

Electron microscopy. Sections of threads contained mycoplasma cells as finely granular bodies without any marked clear inner zones (Pl. 2, fig. 6). They were relatively closely packed in the centre of the thread, but became progressively further apart towards the periphery.

\section{Examination of threads after immersion in antiserum}

Optical microscopy. After immersion in antiserum and with dark-ground illumination the rather diffuse hazy outline and milky white colour of the thread slowly began to sharpen and within a few minutes became refractile and brighter, reminiscent of a crystallization process (PI. I, fig. 4). Normal serum did not have this effect (Pl. I, fig. 5). The addition of complement to the specific antiserum did not appear to affect the 'crystallization process'. 
Electron microscopy. After exposure to antiserum an electron-dense homogeneous precipitate was clearly seen at the edge of the thread, where the mycoplasma cells were arranged close together within the precipitate (Pl. 2, fig. 7). Some precipitate free from mycoplasma cells could also be seen outside the thread margin. In addition to the electron-dense precipitate, a fine granulation was also seen, both outside and within the thread (Pl. 2, fig. 7). Mycoplasma cells which had become separated from the thread were observed within the electron-dense precipitate beyond the edge of the thread. This precipitate took the form of an electron-dense homogeneous capsule round each organism but frequently embraced more than one organism when they were in close proximity (Pl. 3, fig. 9).

Examination of threads that had been immersed in normal sheep serum showed no precipitate and no evidence of a capsule round any mycoplasma cell. Fine granular material was, however, evident within and without the thread substance. Towards the centre of the thread a clear halo, outlined by this granular material, was frequently seen around individual mycoplasma cells (Pl. 3, fig. 8). This halo was sometimes observed also around mycoplasma cells in the centre of a thread that had been submerged in specific antiserum. The addition of complement to either the normal serum or specific antiserum appeared to have no effect on the mycoplasma cells nor on the precipitate.

Threads that had been immersed in globulin had an electron-dense precipitate at the margin, but there was very little granulation within or outside the thread.

\section{DISCUSSION}

Mycoplasma mycoides threads appear to be composed of a mass of filamentousphase mycoplasma cells within a slightly mucinous homogeneous matrix. The individual cells are granular without any marked clear zones inside them, unlike the cells observed at a later stage of growth when the threads have dispersed. The matrix is almost electron-transparent, only becoming electron-dense when treated with specific antiserum. It stains with PAS, and it has also been shown that the addition of glucose to the medium causes thicker threads to be formed (Gourlay \& MacLeod, I966) indicating that the threads may be formed by products of glucose metabolism. A specific carbohydrate has been isolated from M. mycoides (Kurotchkin, 1937; Dafaalla, 1957), and Buttery \& Plackett (1960) showed that it was a galactan and amounted to $10 \%$ of the dry weight of the organism. A similar galactan-containing lipo-polysaccharide was also shown to be present in blood and exudates of cattle infected with $M$. mycoides (Gourlay, 1964). Following evidence that the addition of the lipo-polysaccharide to viable organisms had an aggressive and virulence-enhancing effect in vivo, it was suggested that this material might be present in the form of a capsule round the organisms (Gourlay, 1963, 1965b). Plackett, Buttery \& Cottew (I963) made the same suggestion following their studies on carbohydrates of some Mycoplasma strains, although they produced no evidence to support this view. They did, however, state that no clear evidence of any capsule had been seen in their electron micrographs. Domermuth, Nielsen, Freundt \& Birch-Andersen (1964), on the other hand, suggested that the small amount of amorphous or floccular extracellular substance that they observed during their ultrastructural studies with different Mycoplasma strains (including $M$. mycoides var. mycoides) might be a capsule or slime layer. 
From the evidence presented here, it would seem that the matrix is probably the galactan-containing lipo-polysaccharide material. There does, however, appear to be some difference between the matrix near the mycoplasma cells and that further away, as is shown by the halo and capsule formation. This difference may be qualitative or only quantitative. The stage of growth of the organisms may be important, since the capsules observed here were associated with actively-growing organisms in the filamentous phase. The addition of specific antiserum produces a precipitation of the capsule, perhaps analogous to the Quellung or specific capsular reaction of the pneumococcus.

It is probable that all strains of Mycoplasma mycoides do not produce an equally large capsule, since it was shown (Gourlay \& MacLeod, I966) that, whereas the highly virulent Gladysdale and the T 2 vaccine strains of $M$. mycoides produced threads, the avirulent $\mathrm{KH}_{3} \mathrm{~J}$ and the $\mathrm{T}_{\mathrm{I}}$ vaccine strains did not, even in liquid medium with added glucose. It has been observed that the Gladysdale strain produces about 5 times the volume and about $\mathrm{I}_{3}$ times the dry weight of centrifuge deposit of the $\mathrm{KH}_{3} \mathrm{~J}$ strain for a similar concentration of particles (Gourlay, unpublished). Both virulent and avirulent strains, however, have the same serologically common galactan-containing lipo-polysaccharides (Gourlay, I965a), so perhaps the difference is only quantitative.

The granulation observed in electron micrographs of threads that had been immersed in either normal or specific antiserum was almost absent from threads that had been immersed in globulin, indicating that the granulation was probably due to the precipitation, by the fixation fluids, of serum components other than specific antibody which had penetrated the thread.

We thank members of the Electron Microscopy Section for advice and assistance, Mr I. Jebbett for some of the photography, and members of the Histology Section and Miss Sara Wyld for technical assistance.

\section{REFERENCES}

Buttery, S. H. \& Plackett, P. (1960). A specific polysaccharide from Mycoplasma mycoides. J. gen. Microbiol. 23, 357.

DafaAlla, E. N. (1957). A study of the antigenic structure of the contagious bovine pleuropneumonia organism. Bull. epizoot. Dis. Afr. $5,135$.

Domermuth, C. H., NiElsen, M. H., FreUnDt, E. A. \& BirCh-ANDERSEN, A. (1964). Ultrastructure of Mycoplasma species. J. Bact. 88, 727.

GoURLAY, R. N. (1963). The antigenicity of Mycoplasma mycoides.D.V.M. andS. thesis, University of Edinburgh.

Gourlay, R. N. (1964). Antigenicity of Mycoplasma mycoides. I. Examination of body fluids from cases of contagious bovine pleuropneumonia. Res. vet. Sci. $5,473$.

GoURLAY, R. N. (1965a). Antigenicity of Mycoplasma mycoides. II. Further studies on the precipitating antigens in the body fluids from cases of contagious bovine pleuropneumonia. Res. vet. Sci. 6, I.

Gourlay, R. N. (1965b). Antigenicity of Mycoplasma mycoides. IV. Properties of the precipitating antigens isolated from urine. Res. vet. Sci. 6, 263.

Gourlay, R. N. \& MACLEOD, A. K. (I966). Fermentation of glucose by Mycoplasma mycoides and its effect on viability. Bull. epizoot. Dis. Afr. 14, 373.

KURotchin, T. J. (1937). Specific carbohydrate from Asterococcus mycoides for serological tests of bovine pleuropneumonia. Proc. Soc. exp. Biol. Med. 37, 2 I.

PierCy, S. E. \& KNIGHT, G. J. (1956). Studies with avianised strains of the organism of contagious bovine pleuropneumonia. A further examination of growth and modification in embryonated eggs. Vet. Rec. 68, 367. 
Journal of General Microbiology, Vol. 54, No. I

Plate I
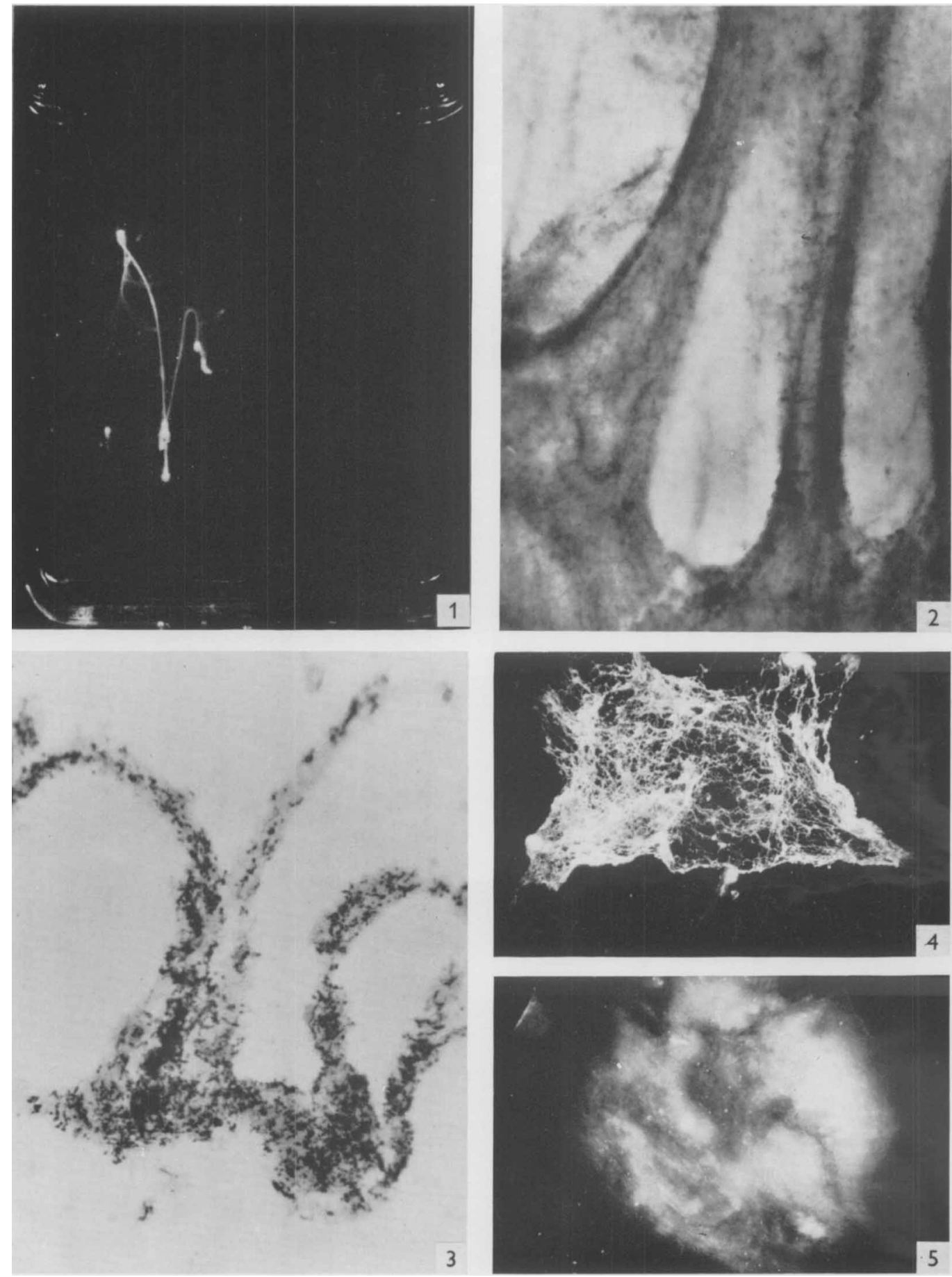

R. N. GOURLAY AND K. J. THROWER 


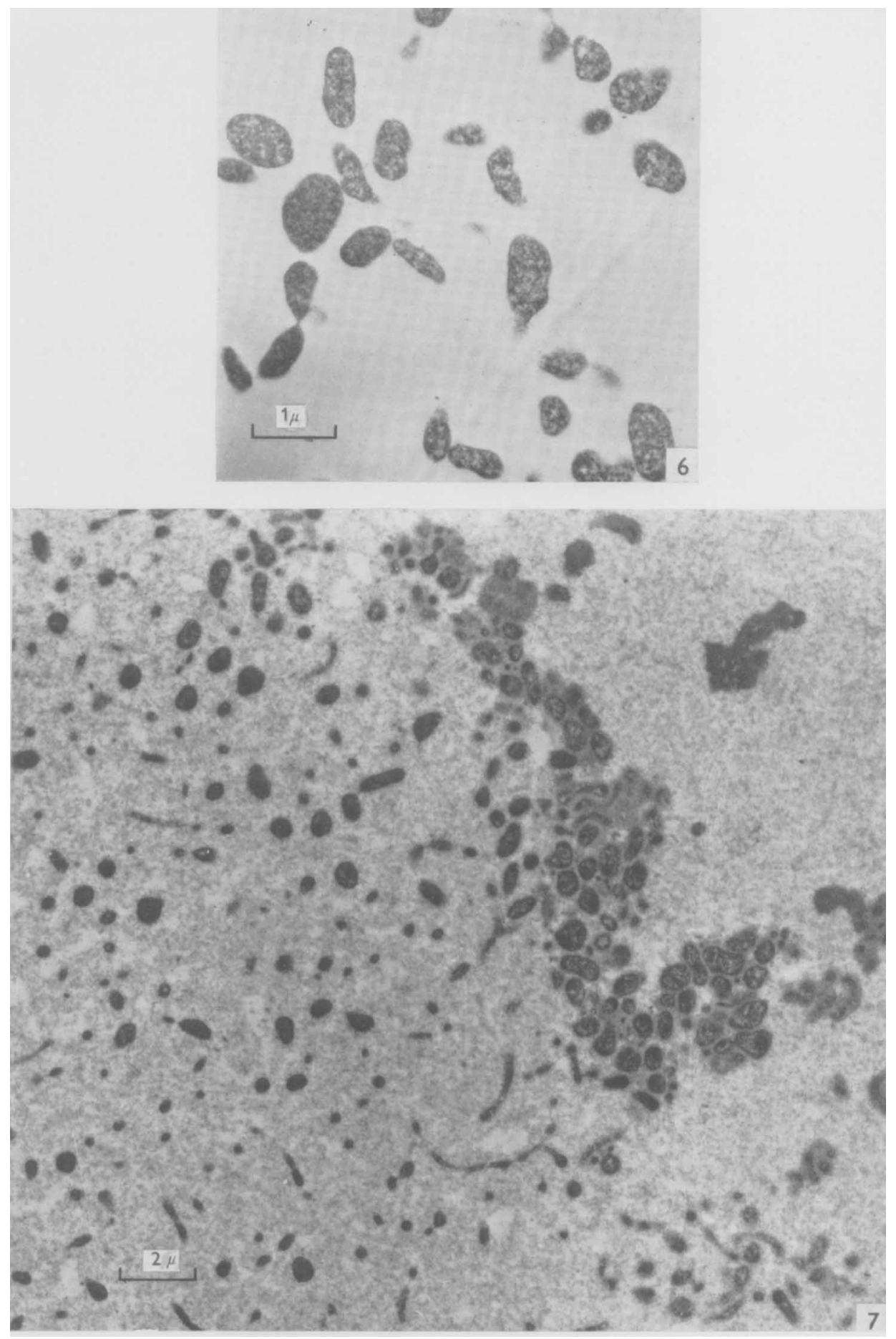

R. N. GOURLAY AND K. J. THROWER 


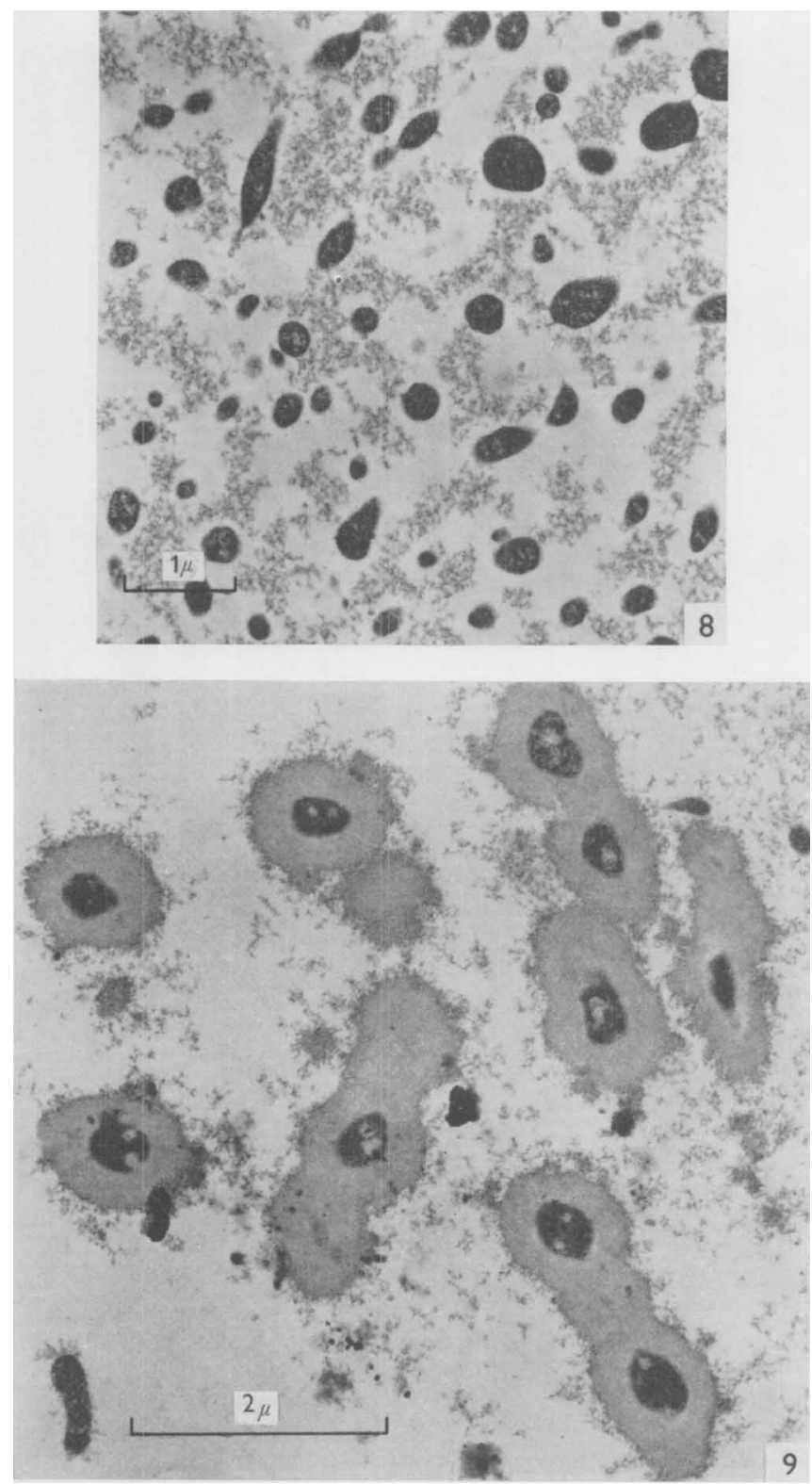

R. N. GOURLAY AND K. J. THROWER 
PLACKetT, P., ButreRY, S. H. \& Cotrew, G. S. (1963). Carbohydrates of some Mycoplasma strains. Recent Progress in Microbiology, 8, 535. University of Toronto Press.

TANG, F. F., Wri, H., McWhirTER, D. \& EdGAR, J. (1935). An investigation of the causal agent of bovine pleuropneumonia. J. Path. Bact. 40, 391.

TURNER, A. W. (1959). Pleuropneumonia group of diseases. In Infectious Diseases of Animals, Diseases due to Bacteria, vol. 2, p. 440. Ed. by A. W. Stableforth and I. A. Galloway. London: Butterworths Scientific Publications.

\section{EXPLANATION OF PLATES}

\section{Mycoplasma mycoides var. mycoides}

\section{Plate I}

Fig. 1. Islands and threads in broth culture. Direct illumination against dark background. $\times 2$.

Fig. 2. Thread spread on a glass slide showing mycelial filaments within a mucinous streaked mass of matrix. PAS-Giemsa, $\times$ II6.

Fig. 3. Thread spread on a glass slide showing mycoplasma cells within a faint matrix. Giemsa, $\times 660$.

Fig. 4. Wet preparation of a piece of thread immersed in antiserum. Dark ground illumination, $\times 23$.

Fig. 5. Wet preparation of a piece of thread immersed in normal serum. Dark ground illumination, $\times 23$.

\section{Plate 2}

Fig. 6. Electron micrograph. Section through the edge of a thread following immersion in antiserum, showing dense precipitate at the margin and granular material within and outside the thread. $\times 5400$.

Fig. 7. Electron micrograph. Section through the centre of an untreated thread, showing mycoplasma cells without marked clear inner zones within an electron-transparent matrix. $\times$ I5,000

\section{Plate 3}

Fig. 8. Electron micrograph. Section through the centre of thread following immersion in normal serum, showing halo formation outlined by granular material. $\times 11,200$.

Fig. 9. Electron micrograph. Section through free mycoplasma cells at the edge of a thread, following immersion in antiserum, showing dense homogeneous capsules round mycoplasma cells. $\times 14,700$. 